\section{Endoscopic ultrasound-guided antegrade dilation of a stenosed hepaticojejunostomy}

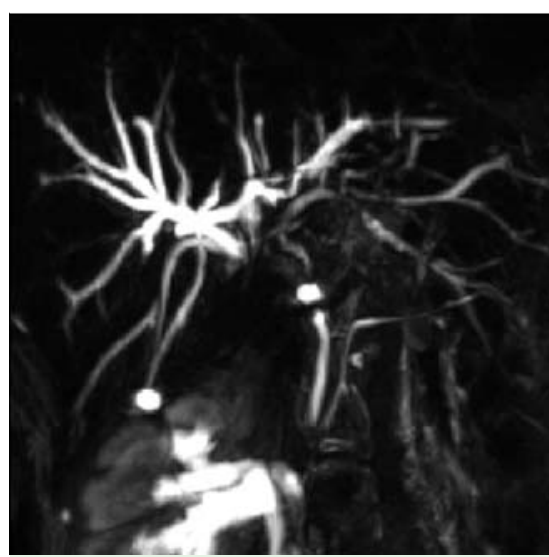

Fig. 1 Magnetic resonance cholangiopancreatography (MRCP) in a 43-year-old woman with cholangitis showing mild dilatation of the intrahepatic biliary radicles and stenosis of the hepaticojejunostomy that had been created for a previous bile duct injury.

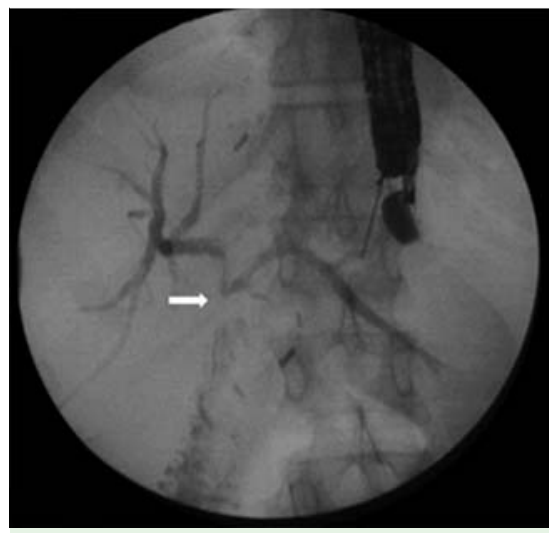

Fig.3 Image taken during an endoscopic ultrasound (EUS)-guided cholangiogram showing stenosis of the hepaticojejunostomy (arrow).
Endoscopic dilation of a strictured hepaticojejunostomy can be performed through an access or afferent loop using a balloon enteroscope or a pediatric colonoscope; however, these can be cumbersome procedures. Alternatively, a percutaneous approach may be utilized, but is associated
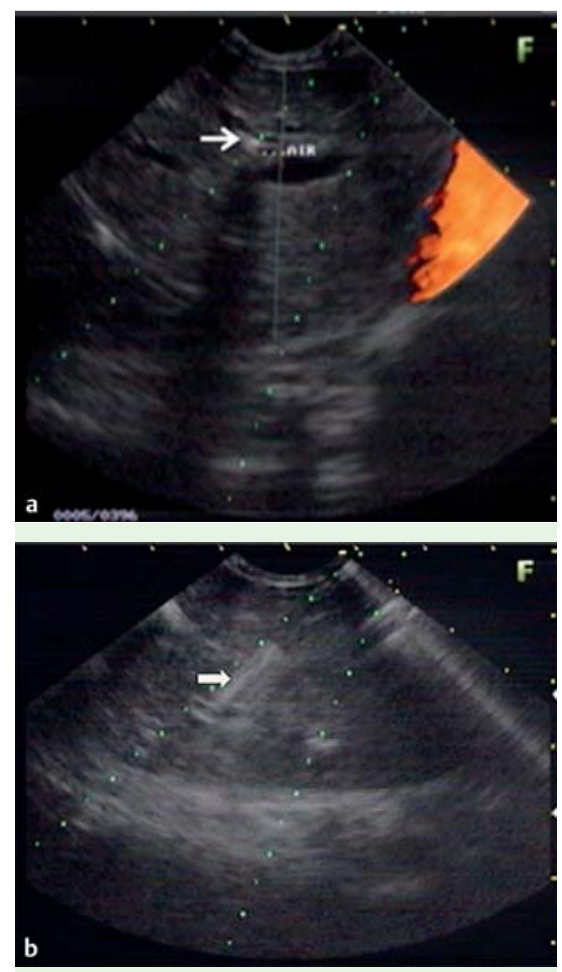

Fig. 2 Endoscopic ultrasound (EUS) views showing: a minimal dilatation of a peripheral bile duct (arrow); $\mathbf{b}$ the peripheral bile duct being punctured by an EUS needle (arrow).
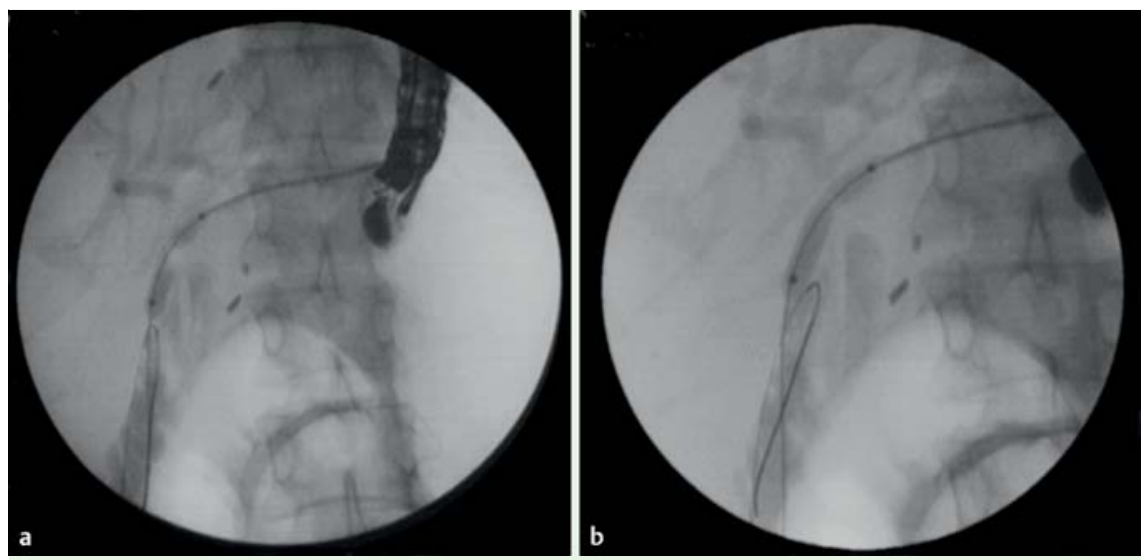

Fig.4 Images taken during balloon dilation of the stenosis showing: a the waist at the start of the procedure; $\mathbf{b}$ disappearance of the waist after dilation for 3 minutes.

with significant morbidity because of the requirement for external drainage catheters. Recently, endoscopic ultrasound (EUS)-guided biliary drainage (EUS-BD) or therapy has been successfully used when retrograde access has failed [1-3]. Here we describe a case involving a stenosed hepaticojejunostomy that was treated by EUS-guided antegrade balloon dilation. To the best of our knowledge, this is only the second such case reported in the literature [4].

A 43-year-old woman presented with repeated episodes of cholangitis over an 18-month period secondary to stenosis of a hepaticojejunostomy that had been created for a previous bile duct injury ( Fig.1). The papilla was inaccessible endoscopically using a double balloon enteroscope because of a long afferent loop and adhesions. The patient was unwilling to undergo percutaneous transhepatic biliary drainage (PTBD).

EUS-guided left duct puncture was therefore performed via a transgastric approach using a therapeutic linear-array echo endoscope (EG530UT; Fujifilm Corporation, Tokyo, Japan). The peripheral intrahepatic left duct, with a diameter of $3.5 \mathrm{~mm}$, was identified ( Fig. 2a) and was punctured using a 19-gauge needle (Echo-tip Ultra; Cook Endoscopy, Winston-Salem, North Carolina, USA; Fig.2b). EUS-guided cholangiography showed mild dilatation of the intrahepatic biliary radicles with a focal anastomotic stricture ( Fig.3). A 0.032-inch, 260-cm hydrophilic guide wire (Terumo Corporation, Tokyo, Japan) was passed through the needle and across the stricture. The tract was dilated over the wire using an ultra-tapered 6-Fr catheter (Cook Endoscopy). The guide wire was then exchanged for a stiffer 0.035-inch wire (Visiglide; Olympus Corporation, Tokyo, Japan).

\section{Video 1}

The technique for endoscopic ultrasound (EUS)-guided antegrade dilation of a stenosed hepaticojejunostomy, including the following steps: (i) puncture of the peripheral left hepatic duct using a 19-guage EUS needle; (ii) taking of a cholangiogram through the needle to demonstrate the stenosis within the hepaticojejunostomy; (iii) negotiation of the guide wire through the stricture; (iv) exchanging of the wire through the catheter; (v) balloon dilation of the stenosis; and (vi) further injection of contrast to show free drainage through the dilated hepaticojejunostomy. 


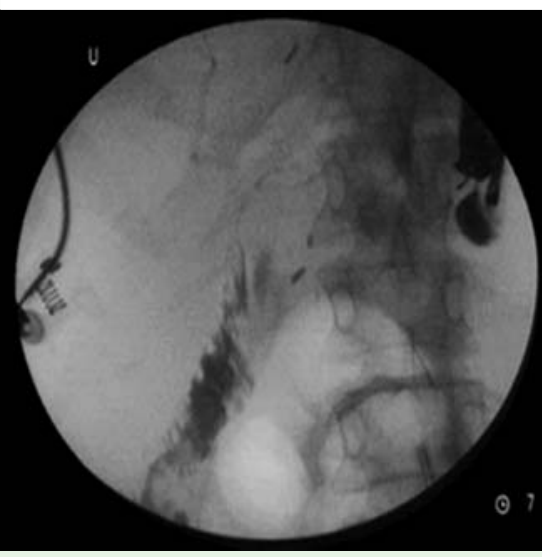

Fig. 5 After the procedure had been completed, a further injection of contrast showed free drainage through the hepaticojejunostomy.

EUS-guided antegrade stenting was deferred in view of the potential difficulty of removal or exchange of the stent at a later date. Instead the stricture was dilated over the wire using an 8-mm balloon dilator (Hurricane; Boston Scientific, Natick, Massachusetts, USA; Fig.4a). Dilation was performed for 3 minutes until the waist disappeared ( $\bullet$ Fig.4b). A repeat injection of contrast drained off easily through the anastomosis ( $\bullet$ Fig.5; - Video 1). No procedural complications were encountered. The patient remained symptom free at the end of 1 month following this single-stage procedure.

Endoscopy_UCTN_Code_TTT_1AS_2AD

Competing interests: None

\section{A. Bapaye, N. Dubale}

Department of Digestive Diseases \& Endoscopy, Deenanath Mangeshkar Hospital and Research Center,

Maharashtra, India

\section{References}

1 Shah JN, Marson F, Weilert F. Single-operator, single-session EUS-guided anterograde cholangiopancreatography in failed ERCP or inaccessible papilla. Gastrointest Endosc 2012; 75: 56-64

2 Dhir V, Bhandari SP, Bapat $M$ et al. Comparison of EUS-guided rendezvous and precut papillotomy techniques for biliary access. Gastrointest Endosc 2012; 75: 354-359
3 Bapaye A, Aher A. Tu1537 Comparison of endoscopic ultrasonography guided biliary drainage (EUS-BD) and percutaneous transhepatic internal biliary stenting (PTBD-S) in patients with malignant biliary obstruction and failed ERCP due to an inaccessible papilla. Gastrointest Endosc 2012; 75: AB438

4 Park DH, Jang JW, Lee SS et al. EUS-guided transhepatic antegrade balloon dilation for benign bilioenteric anastomotic strictures in a patient with hepaticojejunostomy. Gastrointest Endosc 2012; 75: $692-695$

\section{Bibliography}

DOI http://dx.doi.org/

10.1055/s-0032-1325894

Endoscopy 2012; 44: E435-E436

(c) Georg Thieme Verlag KG

Stuttgart · New York

ISSN 0013-726X

\section{Corresponding author}

\section{A. Bapaye, MD}

Dept. of Digestive Diseases and Endoscopy Deenanath Mangeshkar Hospital and Research Center

Pune 411004

Maharashtra

India

Fax: +91-20-40151969

amolbapaye@gmail.com 